
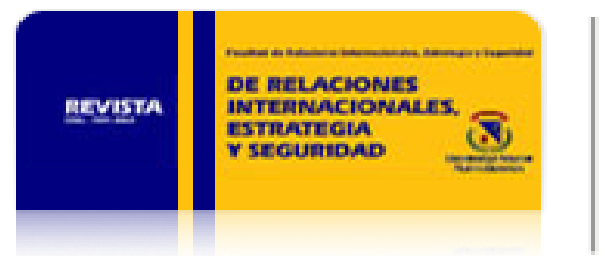

Revista de Relaciones Internacionales, Estrategia y Seguridad

ISSN: 1909-3063

cinuv.relinternal@unimilitar.edu.co

Universidad Militar Nueva Granada

Colombia

Delgado Barón, Mariana

PROTESTA E INSURRECCIÓN FRENTE AL FRACASO DEL MERCADO: LA APUESTA DE LOS MOVIMIENTOS ANTIGLOBALIZACIÓN, «PORQUE OTRO MUNDO ES POSIBLE»

Revista de Relaciones Internacionales, Estrategia y Seguridad, vol. 4, núm. 2, julio-diciembre, 2009,

pp. 13-37

Universidad Militar Nueva Granada

Bogotá, Colombia

Disponible en: http://www.redalyc.org/articulo.oa?id=92712972008

Cómo citar el artículo

- Número completo

- Más información del artículo

Página de la revista en redalyc.org

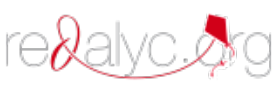

Sistema de Información Científica

Red de Revistas Científicas de América Latina, el Caribe, España y Portugal

Proyecto académico sin fines de lucro, desarrollado bajo la iniciativa de acceso abierto 
rev.relac.int.estrateg.segur.4(2):13-37,2009

\title{
PROTESTA E INSURRECCIÓN FRENTE AL FRACASO DEL MERCADO: LA APUESTA DE LOS MOVIMIENTOS ANTIGLOBALIZACIÓN, «PORQUE OTRO MUNDO ES POSIBLE»
}

\author{
Mariana Delgado Barón*
}

\section{RESUMEN}

Los movimientos alterglobalización, más conocidos como movimientos antiglobalización, constituyen una de las respuestas frente al fracaso del mercado y sus promesas no cumplidas. La apuesta por una globalización alternativa, más incluyente y justa, ha hecho que estos movimientos aprovechen los recursos que ofrece el mismo escenario global, para difundir su mensaje sobre las consecuencias sociales y el impacto medioambiental del modelo de producción imperante, los efectos del libre comercio en las economías de los países en vías de desarrollo, la pobreza y otros grandes temas a través de los cuales se articulan sus propuestas. El presente artículo se encuentra orientado a resaltar las dinámicas de acción de los

\footnotetext{
* Politóloga y Magister en Ciencia Política de la Universidad de Los Andes, Magíster en Política Internacional de la Universidad de Birmingham., actualmente realiza estudios de Doctorado en Ciencias Sociales con Mención en Sociología en la Facultad Latinoamericana de Ciencias Sociales FLACSO, sede México. mariana.delgado@flacso.edu.mx.
} 
movimientos alterglobalización, teniendo en cuenta el contexto global en el que surgen, realizando un acercamiento general a la experiencia boliviana, particularmente respecto a la interacción entre las dimensiones local- nacional- regional e internacional, presentes en este caso, que particulariza estos movimientos.

Palabras clave: protesta, mercado, movimientos antisistémicos, movimientos antiglobalización.

\section{ABSTRACT}

The Alterglobalization Movements, best known as anti-globalization movements, constitute one of the responses to the market failure and its non- accomplished promises. The wager for an alternate globalization, more inclusive and fair has driven these movements to take advantage of the resources the global scenario offers, to spread their message about the social consequences and environmental impact of the prevailing productive model, the effects of free trade on the developing countries' economies, poverty, and other important issues. The article is oriented to highlight the dynamics of action of these movements, taking into account the global context in which they emerge, and to present in general terms the Bolivian case, in particular the interaction among the local- nationalregional and international dimensions that particularize these movements.

Key words: protest, market, antisistemic movements, anti-globalization movements.

\section{INTRODUCCIÓN}

El artículo tiene por objetivo presentar el tipo de respuestas sociales que se han gestado desde diversas organizaciones y movimientos, agrupados bajo el calificativo de «antiglobalización», frente al fracaso del mercado y a las mismas promesas incumplidas de los organismos e instituciones globales como el FMI y el BM. Particularmente, se busca resaltar las dinámicas de acción de las protestas que encierran estos movimientos, teniendo en cuenta el mismo contexto global en el que surgen. El «escenario global» ha sido el espacio en el que se han venido presentando movimientos sociales con un alcance e impacto que excede lo local, e incluso lo regional, en los que se articulan grandes temas globales referentes al medio ambiente, al comercio justo, a la condonación de la deuda externa de los países pobres, la pobreza, los efectos del libre comercio en las economías de los países en desarrollo y las consecuencias sociales del modelo de producción imperante, entre otros.

Estas protestas y formas de insurrección, que se conciben a sí mismas como movimientos de resistencia global o movimientos «alterglobalización" porque apuestan por otra globalización que sea una alternativa al capitalismo, constituyen formas de resistencia a las políticas neoliberales y, a su vez, buscan dar cuenta del fracaso del mercado. Estos movimientos antiglobalización hacen parte del conjunto de movimientos, denominados por Wallerstein, «antisistémicos», caracterizados por 
un marcado rasgo universalista que comparten ciertas similitudes, a pesar de sus particularidades, respecto a su estrategia de acción, procesos de movilización popular y el sentido histórico de cambio social. Específicamente, estos movimientos autodenominados de "alterglobalización», al plantear la lucha contra las consecuencias negativas y aquellos males sociales producto del neoliberalismo, establecen como fundamento la premisa de que "otro mundo es posible», siendo las movilizaciones de resistencia mundial que se dieron en contra de la Ronda del Milenio de la OMC, en la ciudad de Seattle, en 1999, el detonante y el punto de referencia de los mencionados movimientos.

Aunque las preguntas por el alcance de las acciones emprendidas por estos movimientos, sus aciertos, desafíos y fracasos constituyen un amplio tema de debate y reflexión, el trabajo se orienta a dejar planteados estos y otros interrogantes y a esbozar algunas de las posibles respuestas que den cuenta de las dinámicas que se inscriben en estas «nuevas formas de acción, de organización, de identidad y de lucha».

Es importante aclarar que, aunque el trabajo se dirige a analizar la protesta e insurrección frente al fracaso del mercado y de la adopción de políticas neoliberales de una forma general y amplia, se hará alusión a la experiencia boliviana como una forma de ilustrar y ejemplificar esas acciones en contextos concretos.

Para los propósitos del trabajo, la estructura del mismo se encuentra organizada de la siguiente manera: en la primera sección se realiza una breve aproximación a las dinámicas de la economíamundo capitalista como sistema mundo actual; en la segunda parte se presentan algunas de las diversas concepciones del proceso de globalización; en el tercer apartado se introduce el debate sobre las promesas no cumplidas de la globalización neoliberal, como una antesala a la cuarta sección, que plantea los rasgos más sobresalientes de la ola antiglobalización a partir de una caracterización de los movimientos alterglobalización, sus propuestas, sus apuestas y sus formas de protesta; en el quinto apartado se realiza un acercamiento a la experiencia boliviana, respecto a la interacción entre las dimensiones local- regional-nacional e internacional, que particulariza a los movimientos antiglobalización; en la sexta y última sección se mencionan algunas consideraciones finales respecto a los temas abordados.

\section{LAS DINÁMICAS DE LA ECONOMÍA-MUNDO}

Wallerstein señala que las etapas de los sistemas sociales, o las totalidades de estos que se han presentado a lo largo de la historia, han sido únicamente dos: los minisistemas y los sistemasmundo, siendo los primeros «entidades» en donde se da una completa división del trabajo y un marco cultural único, vinculado a sociedades agrícolas o de caza y recolección que "ya no existen en el mundo actual»; y relacionándose los segundos con «unidades con una única división del trabajo, y múltiples sistemas culturales». Los sistemas-mundo, a su vez, se encuentran subdivididos en dos tipos: los imperios - mundo y las economías- mundo; los primeros de estos asociados con 
«estructuras políticas extensas», como es el caso de las grandes civilizaciones del mundo moderno, como China o Roma; los segundos, estrechamente relacionados con el desarrollo del capitalismo desde el siglo XVI (Wallerstein; 2004: 88, 89).

Para Wallerstein, la economía mundial capitalista, como sistema- mundo actual, se compone de tres elementos principales a saber: la existencia de un solo marco de acción que se basa en la obtención del máximo beneficio; la coexistencia de estructuras estatales con diferente capacidad de acción y, por ende, con diferente posibilidad de ejercer poder, y la configuración del espacio mundial en tres zonas alusivas a los Estados del centro, los de la semiperiferia y los de la periferia, siendo los segundos el componente más dinámico de la economía-mundo. Esta división de mundo en tres zonas claramente diferenciadas, que se han integrado a la economía - mundo, también de una forma diferenciada o desigual, «han multiplicado y agudizado los conflictos en el sistema mundial porque éste no sólo produce inmensas riquezas, sino también una inmensa pobreza. Las muestras de la desigualad global siguen una tridivisión del espacio social en centro, semiperiferia y periferia, una división del mundo que integra el sistema mundial de manera conflictiva» (Beck; 1998: 59).

Dado lo anterior, "la división axial del trabajo» en la economía-mundo capitalista implica que la producción se encuentre dividida en: productos centrales y productos periféricos. En esta división de la producción, asociada con la existencia de un centro y de una periferia (además de la semiperiferia), el grado de ganancia es diferencial y, a la vez, relacional para estas regiones en las que se subdivide la economía - mundo. Por una parte, los procesos de producción en el centro se encuentran en manos de "cuasimonopolios», mientras que en la periferia se dan mediante una dinámica competitiva; de esta forma, "cuando ocurre el intercambio, los productos competitivos están en una posición más débil y los cuasimonopólicos en una posición más fuerte», fenómeno que resulta en un «flujo constante de plusvalía de los productores de productos periféricos hacia los productores de productos centrales», produciéndose así un intercambio desigual (Wallerstein; 2005: 46).

Del mismo modo, si los procesos de producción de tipo cuasimonopólico se encuentran focalizados en pocos Estados, los procesos de producción de la periferia se localizan en muchos Estados, los primeros de estos Estados pueden recibir el nombre de centrales o de centro, y los segundos pueden ser denominados como periféricos o de la periferia, sin olvidar que existen también Estados de la semiperiferia que combinan la producción de productos centrales y periféricos, siendo «su mayor preocupación mantenerse a distancia de la periferia y hacer lo posible para acceder al centro» (Wallerstein; 2005).

Por otra parte, la unidad doméstica que predomina en los diferentes tipos de Estado de la economía - mundo capitalista representa, a su vez, la dinámica centro - periferia que reproduce los patrones de desigualdad innatos a este sistema mundo actual. En el centro predomina una unidad doméstica proletaria, mientras que en la periferia sobresale una unidad doméstica semiproletaria.

La coexistencia de procesos de producción del centro, de la periferia y la mezcla de ambos que se da en los Estados de la semiperiferia, ha generado serias tensiones estructurales que, a su vez, 
producen constantes crisis en el sistema que podrían conducir al mismo a una transformación o desintegración. Las presiones económicas, políticas e ideológicas que enfrenta el sistema-mundo de la actualidad reflejan dos contradicciones del capitalismo como modo de producción alusivas «al impulso de cada empresario para maximizar la competencia y reducir los costos y la imposibilidad de obtener beneficios en una economía - mundo expansiva y competitiva si existe una demanda mundial real insuficiente» y a la anarquía de la producción en la que «los intereses de cualquier empresario como competidor tienden a ser contrarios a sus intereses como miembro de una clase» (Wallerstein; 2006: 28). Como resultado de estas dos contradicciones surgen fases de expansión, pero también de estancamiento de la economía-mundo, que tiende a producir como resultado movimientos antisistémicos.

Estos movimientos antisistémicos reflejan una conciencia política, preocupada por diversas problemáticas causadas por el mismo sistema imperante, como lo son el alto grado de mecanización de la producción, la eliminación de limitaciones espaciales para el intercambio de mercancías y de información, la desruralización del mundo, el agotamiento del ecosistema, el alto nivel de modernización del proceso del trabajo y el consumismo. De forma similar, tales movimientos ponen de manifiesto la necesidad de transformar el sistema y así reconfigurar el ordenamiento mundial y sustentarlo en bases sólidas de igualdad para el conjunto de la población.

La conflictividad innata a la economía-mundo capitalista ha desatado una serie de respuestas o «reacciones antioccidentales, antimodernas y fundamentalistas», así como protestas provenientes de diferentes movimientos y formas de insurrección que buscan dar cuenta de los problemas de alcance global que ha traído el mismo proceso de globalización; "la lógica interna del sistema mundial capitalista produce dos cosas opuestas: integración y desmoronamiento mundial» (Beck; 1998: 59).

En esta misma dirección, George Soros, citado por Carlota Pérez, establece que «hay un punto a partir del cual la perturbación en la periferia no puede ser beneficiosa para el centro", y que, además, "el sufrimiento en la periferia se ha hecho ya tan intenso que algunos países han comenzado a salirse del sistema global, o simplemente a quedarse al margen» (Pérez; 204: 163). Igualmente, anota Pérez, "cuando llegan al máximo las tensiones económicas estructurales conducentes a una burbuja insostenible, el resultado está escrito en la pared: sobreviene algún tipo de quiebre seguido de una seria recesión. Lo que no se puede predecir es la forma específica como la sociedad superará esas tensiones» (204: 163). La forma en que estas tensiones provocadas por el sistema se han manifestado en la escena internacional en los últimos años, ha sido a través de los movimientos antiglobalización que, como se plantea en los próximos apartados, denuncian y protestan en contra de los efectos negativos que las dinámicas globalizantes de la economíamundo capitalista han producido en los ámbitos sociales, políticos, culturales y económicos, desde el ámbito local, hasta el global. 


\section{SOBRE LA GLOBALIZACIÓN: ¿QUÉ ES?}

No existe un consenso sobre la definición o conceptualización del fenómeno de la globalización ni sobre las dimensiones que dicho fenómeno implica, así como no se ha establecido un acuerdo sobre sus orígenes, que puede estar situado en el siglo XVI, según autores como Wallerstein, o ya entrado el siglo XX. No obstante, como lo mencionan Held y McGrew, "para comprender la globalización contemporánea es preciso ubicarla en el contexto de las tendencias seculares del desarrollo histórico mundial (...) marcado por distintas fases» (2003: 18).

No obstante, a pesar de las discrepancias en torno a los orígenes de la globalización, Beck (1998) argumenta que existe una suerte de "común denominador» acerca de este proceso que establece el reemplazo de una de las principales premisas de la modernidad: la concepción de actuar y de vivir en los espacios territorialmente establecidos y delimitados por los Estados nacionales como Estados territoriales. Esta premisa ha sido sustituida por la "pérdida de fronteras del quehacer cotidiano", no sólo en su dimensión social, sino también en sus dimensiones política, económica y técnica, por mencionar algunas.

En esta misma dirección, para Rosenau la globalización implica que se ha pasado de una etapa en la que la política internacional aún se encontraba liderada por los Estados nacionales, a una etapa post-nacional, que configura un escenario internacional compartido por los Estados y otros actores no estatales, de tipo transnacional. La transición de una etapa nacional a una post-nacional también viene acompañada de un reemplazo de la estructura de poder monocéntrica, sustentada en los Estados nacionales, a una estructura policéntrica en la que «una pluralidad de actores transnacionales y nacionales-estatales compiten o, en su caso, cooperan entre sí» (Rosenau citado por Beck; 1998: 61). Sin embargo, aclara Rosenau, los dos espacios o ámbitos de la sociedad global, denominados como «la sociedad de los Estados» y el «mundo de la subpolítica transnacional», conformados también por actores diferentes a los Estados nacionales, coexisten en el espacio de la política mundial policéntrica, en donde aquellos que interactúan detentan diversas capacidades y oportunidades de poder.

El paso a una estructura policéntrica del poder que rige la política mundial se encuentra acompañado por una mayor importancia de la dimensión tecnológica de la globalización, que ha puesto fin a "los distanciamientos geográficos y sociales», hecho que ha contribuido a fortalecer la dependencia mutua entre diversos ámbitos sociales y políticos del orden local, nacional y global (Rosenau, citado por Beck; 1998: 62).

Del mismo modo, la eliminación de las barreras espacio-temporales, producto de la interdependencia, de los avances en el campo de la informática y del aprovechamiento de los recursos tecnológicos, permite identificar algunos de los rasgos más sobresalientes de la política mundial policéntrica: la coexistencia en el mismo espacio mundial de diversos actores con una naturaleza marcadamente diferenciada, como el caso de la Iglesia católica, los carteles de la droga y el FMI; el 
aumento de problemas transnacionales que, como bien lo indica su nombre, produce efectos en todo el globo, como el tráfico de drogas, el calentamiento global y la trata de personas; el auge de los eventos transnacionales, que generan una opinión pública también transnacional; la conformación de comunidades transnacionales con bases religiosas o políticas, entre muchas otras; y la configuración de estructuras transnacionales que permean desde el trabajo hasta la producción (Beck; 1998: 62, 63).

Gilpin, por su parte, establece que las dinámicas de la globalización deben ser entendidas a partir de la existencia de un orden global permisivo, constituido por Estados que «sólo permiten que se creen, destruyan y mantengan dependencias y redes de relaciones más allá de y entre autoridades nacionales-estatales»; en otros términos, las condiciones a partir de las cuales se produce y reproduce la globalización son el producto de la autoridad nacional, «la globalización presupone, por así decir, el permiso tácito por parte del Estado» (Beck; 1998: 63). Sin embargo, el argumento de Gilpin demuestra ser poco convincente cuando han sido los procesos globalizadores los encargados de socavar la capacidad de acción de los Estados nacionales, y cuando los espacios de toma de decisión se han trasladado a estancias o ámbitos supranacionales, en los que la autonomía y soberanía nacional pierden relevancia.

La globalización, como fenómeno que encierra dimensiones variadas como la cultural, la económica, la política y la tecnológica, por mencionar algunas, difiere de la internacionalización y de la transnacionalización, pues implicó un aumento de las interdependencias y el incremento de las redes de tipo económico y cultural, sustentadas en una base mundial (Canclini; 2000: 46). La globalización como proceso implica "la simultaneidad, coexistencia e interdependencia entre los aspectos socio-económicos, tecnológicos, ideológicos y culturales», por mencionar algunos (Sotolongo; 2006: 184).

La interdependencia creciente que caracteriza al proceso de globalización involucra entonces una mayor «interacción» entre los diferentes centro de producción, circulación y consumo, el aumento de «flujos» en las comunicaciones y las migraciones, y la desregulación de las transacciones internacionales, entre otros factores, de tal forma que es posible afirmar que la globalización «es un nuevo régimen de producción del espacio y el tiempo" (Canclini; 2000: 47). En términos más concretos, la globalización implica que los impactos de «los flujos y patrones transcontinentales de interacción social» sean más profundos, crecientes y acelerados, produciendo un cambio considerable en los sistemas de organización social, particularmente en las posibilidades de conexión entre estos y en el alcance de las relaciones de poder. Con la globalización se produce un cambio considerable en los patrones estructurales que rigen el ámbito social y el mismo ordenamiento mundial. Especialmente, las transformaciones generadas en los factores organizacionales del ámbito socio-económico de las estructuras territoriales y de las relaciones de poder han llevado a que la globalización configure nuevas formas de "organización social transnacional» y de un nuevo significado y «reordenamiento» a la relación entre el territorio y las esferas política, social y económica (Held et. al; 2003: 13). 
Para Beck, la globalización se concibe como un proceso mediante el cual se configuran vínculos y se crea una espacialidad social de tipo transnacional, de tal forma que el rasgo particular de la globalización consiste en «la ramificación, densidad y estabilidad de sus recíprocas redes de relaciones regionales-globales, empíricamente comprobables y de su autodefinición de los medios de comunicación, así como de los espacios sociales y de las citadas corrientes icónicas en los planos cultural, político, militar y económico» (1998: 31). Con la puesta en marcha del proceso de globalización, se pone en marcha también la transnacionalización de las relaciones, de las transacciones y del consumo, al mismo tiempo que se da un proceso de "traslocalización» de las comunidades, el trabajo y el capital, así como surge una mayor conciencia global de las problemáticas mundiales referentes al daño medioambiental, la pobreza y la desigualdad en un escenario global que carece de un gobierno mundial (Beck; 1998: 31, 32).

En esta misma dirección, Sotolongo manifiesta que la globalización se ha constituido en una «red distribuida de conectividad cada vez mayor de las actividades humanas, que trascienden más y más las fronteras nacionales, así como de retroalimentaciones mutuas entre esas actividades»; asimismo, la globalización implica el constante incremento de las transacciones financieras y flujos de capitales, que se sustenta a su vez en la inmediatez que proporcionan las telecomunicaciones (2006: 180, 181). En sus orígenes, esta red de conectividad, que supone la globalización, estuvo constituida de «abajo hacia arriba» hasta que instancias internacionales como el BM, el FMI y la OMC se apropiaron o aprovecharon mejor esta red para reorientarla en la dirección de "arriba hacia abajo», y para cimentarla en fundamentos de corte neoliberal. Dada esta reorientación del proceso de globalización, Sotolongo afirma que «la globalización neoliberal constituye (...) un ejemplo de un tipo de conjugación de los mecanismos sociales espontáneos, que actúan y se propagan de abajo hacia arriba en la sociedad, con los mecanismos sociales directivos, que se dirigen de arriba hacia abajo y que, en este caso desde determinados centros de poder encauzan lo emergido hacia una orientación de valores predefinida que, como ha mostrado la experiencia reciente, hace abortar muchas de las potencialidades socialmente legítimas y de enriquecimiento humano de lo emergido» (2006: 181).

La ausencia de un consenso conceptual y teórico en torno a la globalización, obedece en parte a lo «fragmentario" como "rasgo estructural de los procesos globalizadores», en otras palabras, "lo que suele llamarse globalización se presenta como un conjunto de procesos de homogeneización y, a la vez, de fraccionamiento articulado del mundo», razón misma por la que este fenómeno no sólo tiende a homogeneizar sino que también ahonda las diferencias y, por ende, las desigualdades (Canclini; 2000: 49- 50). En este sentido, la globalización ha posibilitado una mayor interdependencia, pero también ha profundizado diferencias y conflictos, «dado que una proporción sustancial de la población mundial está ampliamente excluida de los beneficios [que ésta produce]. La irregularidad de la globalización impide que sea un proceso universal que se experimenta de forma uniforme en todo el planeta» (Held, et al.; 2003: 13), incluso, ha producido que "comunidades, países e incluso continentes enteros» se encuentren desvinculados o desconectados, en palabras de Arrighi, del "sistema de abastecimiento mundial», generando problemas de orden que inciden en el mantenimiento de la ley y que la violencia producida no pueda ser controlada o contenida por los propios Estados nacionales (1999: 397- 398). 
Por otra parte, Canclini señala que el fenómeno de la globalización se concibe «como expansión de los mercados y, por tanto, de la potencialidad económica de las sociedades», en este sentido, «la globalización estrecha la capacidad de acción de los Estados nacionales, los partidos, los sindicatos y en general de los actores políticos clásicos. Produce mayor intercambio transnacional y deja tambaleando las certezas que daba el pertenecer a una nación» (Canclini; 2000: 21). De esta forma, la globalización no sólo hace que las decisiones políticas sean tomadas ahora en instancias supranacionales o incluso transnacionales, sino que a su vez esto deriva en una pérdida de la capacidad de maniobra y de acción de los Estados nacionales para manejar los destinos de sus propios países, Ilevándolos a «atrofiar su imaginación socioeconómica y a olvidar las políticas planificadoras de largo plazo» (Canclini; 2000: 21). En esta misma dirección, Held y McGrew resaltan el desafío que enfrentan los gobiernos nacionales frente a «una amalgama de sistemas de gobernanza globales, regionales y de múltiples niveles» que los obligan a diseñar sus agendas nacionales de acuerdo con las pautas dictaminadas por instituciones y organismos supraestatales (2003: 31, 35).

Esta pérdida del protagonismo de los Estados nacionales que mencionan Canclini, Held y McGrew, que se encuentra acompañada de un debilitamiento de las propias «instancias democráticas nacionales», alimenta el proceso de dependencia creciente tanto cultural y económica de los Estados del Sur o de la periferia hacia los Estados del centro que dominan los procesos de globalización (Canclini; 2000: 22). En este mismo sentido, la "correspondencia directa entre sociedad, economía y Estado dentro de un territorio nacional exclusivo y circunscrito» se ve socavada por la desvinculación de las esferas política, social y económica al ámbito del territorio delimitado del Estado que, aunque no deja de ser importante, sí ha implicado su redefinición y acomodamiento a la realidad global (Held et. al; 2003: 20). La globalización en su dimensión política implica «una salida de lo político del marco categorial del Estado nacional», en otras palabras, al estar los Estados nacionales «entremezclados e imbricados» con actores transnacionales, tienden a perder protagonismo y poder en un proceso que se dirige hacia la «desnacionalización» como factor de erosión del Estado nacional (Beck; 1998: 34).

Con la globalización no sólo se reconfigura la relación sociedad- economía- Estado- territorio, también se reconfiguran y replantean las relaciones de poder en los niveles local regional, nacional y global, hecho que incide directamente en las formas que adquiere la dimensión política. Los cambios experimentados en este ámbito se orientan hacia una "política global», constituida por un amplio y complejo conjunto de redes e interacciones que no se relacionan únicamente con «las cuestiones tradicionales de geopolítica sino también con una amplia gama de cuestiones económicas, sociales y ecológicas» (Held; 2003: 29).

Respecto a la dimensión económica de la globalización, los defensores de ésta (los globalistas) argumentan que la economía contemporánea tiene un carácter global en la medida en que ésta "trasciende e integra las principales regiones económicas del mundo», aunque los llamados «escépticos» resaltan la existencia de zonas centrales y periféricas que no gozan por igual de los 
«beneficios» que ésta produce. Asimismo, la economía global capitalista y «postindustrial», como lo resaltan Held y McGrew, es más propensa a crisis económicas, y ha llevado a los gobiernos nacionales «a adoptar crecientemente estrategias económicas similares que promueven la disciplina financiera, la desregulación y la gestión económica prudente» (Held; 2000: 68).

Respecto al capital financiero, que rige los destinos de la economía global, cabe resaltar que, como lo plantea Arrighi, éste no constituye ni una «etapa particular» ni la «última y más elevada», sino que, por el contrario, ha sido «un fenómeno recurrente que ha marcado la era capitalista desde sus inicios más primigenios» (1999: 8). Incluso, se han presentado varias expansiones financieras que encierran la existencia de ciclos sistémicos de acumulación, desde los que se direcciona y orienta la economía-mundo capitalista.

Cabe resaltar que durante la historia del capitalismo las crisis que se han presentado en el sistema, así como los procesos de reestructuración del mismo, han sido fenómenos constantes que han propiciado la «reconstitución de la economía-mundo capitalista a partir de nuevos y más ambiciosos fundamentos (...)» (Arrighi; 1999: 13). Lo importante es destacar que en estos procesos de crisis de los últimos años, el Estado, o más específicamente su capacidad de maniobra y acción frente a las contingencias del mercado, «ha quedado a merced de la disciplina financiera», debilitando el supuesto equilibrio entre él y el poder financiero, a favor de éste último.

\section{LAS PROMESAS NO CUMPLIDAS}

Algunos de los factores o elementos en los que el proyecto neoliberal, configurado como una respuesta y reacción al intervencionismo estatal y a una de sus expresiones, el Estado de Bienestar, se encuentra cimentado, aluden a: considerables recortes en el gasto social, las medidas de privatización, la mano dura hacia el sindicalismo y las huelgas, una fuerte disciplina en asuntos monetarios y fiscales y el control del déficit de las finanzas públicas.

La globalización neoliberal, sustentada, como su nombre lo indica, en la ideología neoliberal, «no ha cumplido con sus promesas de beneficio económico» para todos, a pesar de los beneficios que puede representar para algunos sectores transnacionales. De esta misma forma, la globalización tampoco ha logrado frenar o reducir la pobreza ni hacer de la estabilidad económica una bandera real; por el contrario, como lo asegura Stiglitz, la crisis y «el temor al contagio financiero» se han extendido no sólo en Asia, sino también en Europa y América, a tal punto que, "durante un tiempo, en 1997 y 1998, la crisis asiática pareció cernirse sobre toda la economía mundial» (2003: 30). En esta dirección, ni la globalización ni la introducción de la economía de mercado han resultado del todo beneficiosas para aquellos países que adoptaron y se ciñeron a los programas de transición hacia el capitalismo, y mucho menos para los países pobres, aquellos de la periferia, que fueron forzados por Occidente a eliminar sus barreras comerciales. 
Dentro de los beneficiados por el conjunto de medidas de flexibilización de los controles en los mercados de la periferia o semiperiferia, se encuentran los bancos de Occidente, a pesar de que esas regiones, por mencionar el caso de América Latina, "sufrieron cuando los flujos de dinero caliente especulativo que se habían derramado sobre los países súbitamente tomaron la dirección opuesta» (Stiglitz; 2003: 32).

No obstante, a pesar de que la globalización neoliberal puede representar beneficios para algunos, estos siguen siendo un conjunto menor en comparación con los «males» producidos o el «precio» a pagar, ya que, señala Stiglitz, no solamente estas medidas neoliberales han tenido un profundo impacto negativo sobre el medio ambiente, sino que también han provocado graves crisis sociales y políticas como el masivo desempleo, el aumento de violencia urbana y el recrudecimiento de conflictos étnicos.

Particularmente, el FMI, constituido como un organismo para garantizar la estabilidad económica mundial e instituido también a fin de evitar una «nueva depresión global», como la sufrida en los años treinta del siglo pasado, ha mantenido su tarea «descargando presión internacional sobre los países que no cumplen con su responsabilidad para mantener la demanda agregada global, dejando que sus economías se desplomen». Asimismo, bajo el fundamento y la necesidad de constituirse en una institución pública, el FMI es controlado por los ministros de Hacienda y por los bancos centrales de los gobiernos que lo conforman, por medio de un mecanismo de votación que, en palabras de Stiglitz, se rige «en buena medida en el poder económico de los países a finales de la II Guerra Mundial».

Sin embargo, el FMI no ha logrado llevar a cabo su tarea, «no hizo lo que supuestamente debía hacer: aportar dinero a los países que atravesaran coyunturas desfavorables para permitirles acercarse nuevamente al pleno empleo»; incluso, las medidas contempladas por el Fondo para aliviar las crisis, terminaron por ahondarlas, particularmente en los países pobres. Más específicamente, el FMI «ha cometido errores en todas las áreas en las que ha incursionado: desarrollo, manejo de crisis y transición del comunismo al capitalismo» (Stiglitz; 2003: 43).

Con estas promesas no cumplidas, sobre todo las relacionadas con un progreso y un beneficio para todos los participantes de la economía- mundo capitalista, aquellos que se vieron relegados del «progreso», del "crecimiento» y de la «riqueza», comenzaron a cuestionar el propio sistema y a protestar en contra de éste. La protesta y la insurrección frente al fracaso del sistema y la imposibilidad de éste para generar igualdad de beneficios para todos, profundizaron la falta de legitimidad de una economíamundo que ha funcionado bajo la lógica de la permanente acumulación de capital de forma exhaustiva, de la mecanización de la producción, de la desruralización del mundo, del agotamiento del ecosistema, del consumismo y de la pauperización permanente de la periferia (Wallerstein; 2004: 4085). Tal falta de legitimidad del sistema se ha reflejado en las respuestas provenientes por parte de los movimientos antiglobalización, que ponen de manifiesto la cuestión sobre la insostenibilidad de la economía capitalista y del sistema de globalización neoliberal que ha producido. 


\section{LOS MOVIMIENTOS ANTIGLOBALIZACIÓN: POR UNA GLOBALIZACIÓN ALTERNATIVA}

Los movimientos antiglobalización son clasificados por Wallerstein como «la más reciente variante» del conjunto de movimientos antisistémicos, término que aparece en escena a partir de la década de los 70 's del siglo XX, para agrupar y denominar a los dos tipos de movimientos populares existentes hasta el momento: los movimientos sociales y los movimientos populares (2003: 100). A pesar de sus diferencias y particularidades, ambos tipos de movimientos lograron en su mayoría consolidarse como «estructuras burocráticas significativas» a partir de la segunda mitad del siglo XIX, bajo las que es posible identificar una serie de características en común, identificadas por Wallerstein:

- Muchos de estos movimientos se concebían como «revolucionarios» y, en este sentido, como partidarios de transformaciones sociales significativas.

- $\quad$ En sus comienzos constituían una fuerza política débil, frecuentemente reprimida por el aparato estatal.

- $\quad$ En su interior se llevaron a cabo importantes debates sobre su estrategia; el argumento ganador planteaba una orientación hacia el Estado (concebido como enemigo), puesto que allí se localizaba el poder real. Con este argumento la estrategia de los movimientos consistía en dos fases: 1. Conquistar el poder; y 2. Transformar el mundo.

- Los movimientos socialistas introdujeron en su discurso un componente nacionalista, mientras que el discurso nacionalista incluyó una retórica social.

- $\quad$ En ambos tipos de movimiento se encuentran similitudes en los procesos de movilización popular.

- Debieron enfrentar la tensión «revolución»- «reforma».

- $\quad$ Fracasaron en su intento de implementar la estrategia de cambio en las dos fases mencionadas.

Concretamente, los movimientos antisistémicos de las últimas décadas corresponden a los nuevos y a los «novísimos» movimientos sociales, cuyo auge se manifiesta en las coyunturas de 1968 y 1999. Esta segunda oleada de movimientos antisistémicos reúne a cuatro tipos de manifestación en contra del sistema: Los múltiples maoísmos, inspirados en la revolución cultural china; los nuevos movimientos sociales, como los feministas y los ecologistas; los defensores de los derechos humanos, y más recientemente los movimientos antiglobalización (Wallerstein; 2003).

Los movimientos denominados como «antiglobalización», prefieren referirse a sí mismos como movimientos alterglobalización, debido a que apuestan por una globalización alternativa a la que ofrece la globalización neoliberal imperante. La Cumbre de la OMC, celebrada en la ciudad de Seattle, en el año de 1999, constituye un momento clave para su aparición en el escenario público. El rasgo más distintivo de estos movimientos lo constituye la base de su participación que se dirige a la «lucha contra los males sociales derivados del neoliberalismo» (Wallerstein; 2003: 101).

Es importante aclarar que las protestas y las formas de insurrección frente al fracaso de mercado y frente a los efectos nocivos que ha generado el proceso de globalización no constituyen un fenóme- 
no «novedoso», sí lo es la explosión de estos movimientos en los países del centro, en donde «sus quejas no solían tener eco» (Stiglitz; 2003: 27).

Otro factor interesante a destacar dentro de los movimientos antiglobalización es que, a pesar de manifestarse en contra de los efectos negativos que ésta ha tenido en la política, la economía y la sociedad, se valen de los recursos y medios tecnológicos que ésta facilita para promover y difundir su propia lucha; es decir, con la globalización se ha dado paso a una mayor interconexión que ha socavado esa «sensación de asilamiento» entre comunidades y países, y es precisamente esa interconexión la que ha posibilitado el alcance de la acción antiglobalizante. El movimiento antiglobalización se articula como una vasta red de grupos de diversa naturaleza, organizaciones no gubernamentales, activistas sociales, sindicatos y un gran conjunto de movimientos sociales que han aprovechado el acceso a la comunicación vía internet para convocar, para difundir, para reclutar y para movilizar en torno a las causas que defienden en pro de un proyecto alternativo de globalización. Respecto al uso de internet como medio para expandir su mensaje, los movimientos antiglobalización han hecho de esta «herramienta» o «recurso» un «nuevo escenario de acción colectiva, de participación, de lucha y de resistencia en lo social y político (...) [que lo convierte en un] mecanismo democrático, [en el que] actores [de diversa naturaleza] construyen nuevos espacios y redes de intercambio, enfocados en abrir nuevas formas de participación virtual» (Sandoval; 2009: 48).

Esta reacción mundial en contra de la globalización neoliberal, pone de manifiesto que ésta «tal y como ha sido puesta en práctica no ha conseguido lo que sus partidarios prometieron que lograría... ni lo que puede ni debe lograr (...) en algunos casos ni siquiera ha generado crecimiento, y cuando lo ha hecho, no ha proporcionado beneficios a todos", así como ha tendido a privilegiar los intereses comerciales sobre los asuntos que tienen que ver con el medio ambiente, los derechos humanos y la democracia (Stiglitz; 2003: 46).

Respecto a la variedad y las particularidades de los mismos movimientos que componen el conjunto del movimiento antiglobalización, el Foro Social Mundial ha tendido a agrupar en un mismo paquete a movimientos de la vieja izquierda, a nuevos movimientos sociales, a organizaciones defensoras de los derechos humanos y a otro tipo de grupos y organizaciones que, como señala Wallerstein, «no son fácilmente clasificables en estas categorías [del mismo modo en que] el Foro intenta agrupar a movimientos provenientes del Norte y del Sur en un único marco" (2003: 101).

Por otra parte, cabe resaltar que el momento de «explosión» o «irrupción» global del movimiento antiglobalización lo constituye el Seattle de 1999, lugar y fecha en la que se da inicio a la Ronda del Milenio de la OMC.

\section{El Seattle de 1999: la puesta en escena de un movimiento antiglobalización global}

Seattle marca un antes y un después para los movimientos antiglobalización (Durán; 2001). En el mismo escenario en el que se iba a llevar a cabo la Cumbre de la OMC para dar inicio a una nueva ronda de negociaciones de liberalización y desregularización comercial, conocida como la Ronda 
del Milenio, el mundo presenció un movimiento de protesta y de revuelta que llevó al fracaso de la Cumbre, «la imagen del capitalismo global se desmoronó en Seattle» (Durán; 2001).

Las acciones de protesta y de denuncia en contra de la Cumbre de la OMC, Ilevadas a cabo en Seattle, adquieren una dimensión global cuando alrededor de 1.500 organizaciones, "a escala planetaria", suscriben un texto de denuncia en contra del libre comercio mundial, conocido como «Parar la Ronda del Milenio». Durán resalta que las actividades de contestación realizadas en Seattle adquieren una dimensión global destacable cuando desbordan el marco territorial, hecho visible a partir de "acciones y movilizaciones de distinto calado, [realizadas] en más de treinta países del Centro, del Sur y (...) también del Este, [en los que] se tiene constancia que tuvo lugar la protesta» (2001: 18).

La protesta masiva en Seattle, que convocó entre 50.000 y 100.000 personas, provenientes de distintas organizaciones, representadas en el sindicalismo, el ecologismo, el anarquismo y otros tantos grupos, refleja una «multiplicidad de subjetividades y tendencias políticas» bajo un solo lema de protesta: «el mundo no es una mercancía» (Durán; 2001).

Un aspecto a resaltar de las movilizaciones que irrumpieron en Seattle, y simultáneamente en otras partes del mundo en 1999, hace referencia al surgimiento de una forma de resistencia en contra de la globalización económica capitalista que da forma y contenido a «un primer ciclo de lucha» global.

Dentro de los grupos y movimientos de protesta que se manifestaron en la masiva movilización de 1999, se encuentran: La Acción Global de los Pueblos AGP, autodefinida como un mecanismo de coordinación internacional en contra de la $\mathrm{OMC}$, que congrega a pueblos indígenas, movimientos campesinos y organizaciones ecologistas, entre otros grupos, con el objetivo de constituir una red internacional en contra de la globalización económica y del neoliberalismo'; Ios Industrial Workers of the World, un sindicato de Estados Unidos con «vocación universal», de tipo radical, opuesto a las «estrategias pactistas y reformistas» que junto con la AGP realiza «un Ilamamiento a la acción global»; la Direct Action Network, que jugó un papel central en la movilización de Seattle, al coordinar grupos de base de Estados Unidos y también de Canadá; los Public Citizen, movimiento de consumidores cuyos reclamos y reivindicaciones incluyen asuntos como la sanidad, el medio ambiente y el comercio justo; la Indigenous Environmental Network, defensora de la causa ecológica y encargada de coordinar las acciones de grupos indígenas desde Canadá, pasando por Estados Unidos y México; la American Federation of Labor- Congress of Industrial Organizations (AFL$\mathrm{ClO}$ ), «sindicato mayoritario de los EE.U», opositor al NAFTA y aliado de varias ONG 's y grupos de inmigrantes; la United Steelworkers of America (USWA), «uno de los sindicatos más activos y combativos en Norteamérica»; los Jobs with Justice, organizado como un «instrumento de solidaridad interprofesional»; los Black Blocks, como grupos anarquistas, y el Independent Media Center, «creado en Seattle como alternativa a la cobertura de los media oficiales de la Conferencia Ministerial de la OMC» (Iglesias; 2004: 11).

\footnotetext{
${ }^{1}$ www.agp.org, consultado el 15 de junio de 2009.
} 
La diversidad de grupos y movimientos de protesta que se congregaron en Seattle constituye un esfuerzo y triunfo significativos en cuanto a la «amplia alianza de sujetos sociales» que se logró conformar en contra de la globalización neoliberal; «indígenas, sindicalistas, pacifistas, anarquistas, ong 's y un sinnúmero de siglas e individuos se dieron cita en las protestas, adelantando lo que hoy es una de las características indiscutibles de los movimientos globales, a saber, su heterogeneidad» (Iglesias; 2004: 13).

\section{El Foro Social Mundial}

EI FSM, como fenómeno político y social, catalogado como «movimiento de movimientos», se autoconcibe como un espacio de lucha contra la globalización neoliberal y, en especial, contra la discriminación, opresión y exclusión que ésta ha producido en el mundo. En el FSM convergen diversas expresiones, que aunque se adhieren de forma consensual a la no violencia, «se presentan dispersos en un continuo entre los polos de la institucionalidad y la insurgencia» (Souza; 183).

EI FSM, como "conjunto de iniciativas de intercambio social» entre diversidad de grupos y movimientos locales, nacionales e internacionales, no puede ser concebido, según de Souza, como la plena unificación y consenso de las formas de lucha y protesta en contra de la globalización, sino que, por el contrario, debe ser entendido como un espacio en el que la insurrección frente al fracaso del mercado se «presenta dispersa en un continuo entre los polos de la institucionalidad y de la insurgencia» (183).

Asimismo, el FSM debe ser entendido a partir de la dimensión utópica que encierra y bajo la cual se establece la "crítica radical» a las devastadoras consecuencias de la globalización en los planos económico, político y social, y mediante la que se cimenta el ideal de una sociedad más incluyente y justa. Más precisamente, como lo establece de Souza, «la dimensión utópica del FSM consiste en afirmar la posibilidad de una contraglobalización hegemónica» (Souza; 186), es decir, la utopía crítica que se defiende en el FSM se sustenta en la idea de que otro mundo más plural y democrático es posible.

El FSM debe ser entendido entonces como un «instrumento» del movimiento antiglobalización, que se autodefine como «un espacio de encuentro e intercambio de experiencias, de debate democrático de ideas y de articulación de propuestas de acción de movimientos sociales, ONGs, redes de activistas y demás organizaciones de la sociedad civil que se oponen a la globalización neoliberal, al dominio imperial y a la guerra» (Gómez; 2004: 225).

Es importante señalar que el Foro se ha constituido como un "proceso permanente y global», orientado a la defensa de un proyecto de globalización alternativa, que tiene dentro de sus principales pilares la defensa de los derechos humanos, la protección del medio ambiente, los valores democráticos, el predominio de la justicia social y la igualdad de "todos los pueblos». La búsqueda de estos objetivos hace del Foro un espacio de «intercambio, debate y articulación» en el que confluyen movimientos, organizaciones y grupos de diferentes partes de mundo, sin la intención de convertirse 
en una «instancia de representación de la sociedad civil mundial». Este carácter plural del Foro y su naturaleza horizontal, no partidista, no gubernamental y no confesional se complementan con su estructura organizativa descentralizada y en red para la articulación de «acciones concretas por la construcción de un mundo diferente, local o internacional» (Gómez; 2004).

El Foro, como instancia de "facilitación" y "cristalización", no debe ser concebido como una entidad creadora de movimientos sociales, puesto que muchas de las organizaciones y grupos que participan en este espacio ya estaban claramente constituidas, además de contar con una dimensión transnacional, debido a las dinámicas del proceso de globalización que configuraron la reorganización del espacio social y de las relaciones de poder a nivel mundial.

Otro aspecto a considerar respecto al FSM tiene que ver con su naturaleza heterogénea, en cuanto a que congrega múltiples expresiones de identidad, diversas concepciones y representaciones sociales y culturales, y variados intereses y recursos alrededor de la causa «altermundista». De esta forma, lo novedoso del Foro "radica en el hecho de ser «inclusivo", tanto en lo que concierne a sus escalas de acción, como a sus temáticas. Es decir, ser eminentemente global, sin dejar de dar abrigo a movimientos y organizaciones sociales locales, nacionales y regionales supranacionales $y$, al mismo tiempo, ser intertemático y hasta transtemático (Santos, citado por Gómez; 2004)». Adicionalmente, lo nuevo del Foro se encuentra presente en tres aspectos: una concepción del poder y de la opresión que desborda la visión tradicional y que cuestiona principios jerárquicos y verticales de articulación social, que son reemplazados por "articulaciones horizontales en redes»; el predominio de los valores de la igualdad y del reconocimiento a la diferencia, y la concepción de la rebelión como no - conformismo que excluye la revolución como mecanismo de acción.

\section{Porque otro mundo es posible}

La globalización para los movimientos antiglobalización ha sido «un proyecto gobernado por las élites políticas y económicas del mundo», que la han convertido en una "cosmocracia», con centro en los Estados Unidos, desde donde se promueve el proyecto globalizador por medio de instituciones como el BM, el FMI y la OMC (Held; 2003: 73). Estas instituciones, como lo defiende el proyecto de la alterglobalización, han permitido la configuración de una especie de gobernanza global, mediante la institucionalización de la política a esta escala, por medio de acuerdos, redes y regímenes regionales y globales que «regulan e intervienen en prácticamente todos los aspectos de la actividad transnacional o de los asuntos del mundo, desde las finanzas globales hasta la flora y la fauna globales» (Held; 2003: 74).

Un punto interesante acerca de las expresiones de los movimientos antiglobalización es que también hacen uso de las posibilidades de proyección de sus acciones, que les ofrece la misma globalización. El ámbito de «la gobernanza global se ha convertido en el [espacio] principal tanto para la promoción como para el rechazo de la globalización», y ha sido escenificada bajo criterios liberales «por cuanto promueve y desarrolla el proyecto de un mundo liberal en el que los merca- 
dos globales, el imperio internacional de la ley, la democracia liberal y los derechos humanos se convierten en normas universales de la civilización» (Held; 2003: 75).

Bajo esta gobernanza global liberal se han congregado diversidad de intereses que provienen de las élites «tecnocráticas y cosmopolitas", y se han sentado las bases para la constitución de una "clase capitalista transnacional» que defiende el proyecto del capitalismo global. Este ámbito global no sólo ha hecho posible la proyección y fortalecimiento de esta clase capitalista, sino que también ha permitido que las expresiones antiglobalización sean visibles y puedan ser escuchadas. De esta forma, el ámbito de la gobernanza global articula intereses corporativos transnacionales y a su vez es aprovechada para combatir a la propia "globalización corporativa", constituyéndose así en un espacio de lucha orientado a la [transformación] de la naturaleza explotadora del presente orden mundial» (Held; 2003: 78). A pesar de que esta gobernanza global debe ser entendida como un complejo sistema compuesto por diversos niveles, dimensiones y actores, su naturaleza o carácter pluralista no implica que todas las partes involucradas detenten iguales derechos o influyan en algún grado en las decisiones a tomar y en la propia agenda, «por el contrario, se reconoce que el sistema está distorsionado a favor de los Estados y los intereses creados más poderosos» (2003; 82).

En la última década han aparecido en la escena global diversos movimientos que conforman un vasto y diverso conjunto constituido por ONG 's y movimientos sociales que han logrado establecer un amplio espectro de acciones y formas de protesta en contra del proyecto de globalización, liderado por corporaciones e instituciones y apoyado por los Estados nacionales. El movimiento antiglobalización, mediante la acción directa, campañas de carácter transnacional y actividades de protesta ha conseguido "atraer la atención del mundo» sobre diversas problemáticas que ha causado el proyecto globalizador, alusivas a una amplia gama de temas que van desde el deterioro medioambiental hasta la condonación de la deuda externa para los países más pobres.

Algunas de las campañas promovidas por estos movimientos han logrado obtener algún nivel de éxito, puesto que han incidido en la «alteración de las agendas de las instituciones globales»; no obstante, para algunos arraigados y radicales críticos de la globalización, el ámbito de la gobernanza global ha sufrido alteraciones mínimas, "cambios cosméticos y nada sustanciales», y han puesto de manifiesto la necesidad de plantear un «sistema alternativo de gobernanza global» que reemplace al orden global imperante por uno que "dé prioridad a las personas por encima de los beneficios» y que ponga en el orden del día las principales preocupaciones de la emergente sociedad civil transnacional (Held; 2003: 79, 83).

En términos más amplios, los movimientos antiglobalización han dirigido y concentrado esfuerzos para incidir en la redefinición de la agenda de la política no sólo local, sino también nacional y global; brindar a las comunidades participación y voz en los foros regionales y mundiales; ejercer presión para que exista una verdadera rendición de cuentas por parte de los organismos y las corporaciones internacionales, y hacer de autoridad moral y técnica frente a las decisiones a tomar (Held; 2003: 84). 
La forma que ha adquirido el movimiento antiglobalización como una respuesta a una gobernanza internacional que ha sido caracterizada por constituir un «sistema de dominación global de los fuertes sobre los débiles", ha estado encaminada a protestar en contra de un modelo neoliberal de libre comercio y libre circulación de flujos que ha generado una considerable desigualdad global, miseria humana y exclusión de la mayoría de la población mundial que no se beneficia del bienestar económico global. De esta forma, con la globalización no sólo se ha acrecentado la desigualdad entre países pobres y ricos, del centro y de la periferia, sino que también esta brecha se ha ampliado al interior de los mismos países, «el mundo ya no está dividido [únicamente], como lo estuvo alguna vez, según líneas geográficas, es decir, entre norte y sur, sino que manifiesta más bien una nueva arquitectura social (...) que reordena al mundo en dos categorías: los ganadores y los perdedores de la globalización» (Castells, citado por Held; 2003: 97).

Dado lo anterior, la dimensión económica de la globalización, o más concretamente la globalización económica, ha sido el principal causante de la desigualdad mundial, debido principalmente a cuatro factores que se relacionan entre sí: «la creciente segmentación de la fuerza de trabajo global en ganadores y perdedores de la integración productiva y financiera; la creciente marginación, exclusión y empobrecimiento de los perdedores tanto entre Estados como dentro de ellos; la erosión de la solidaridad social, dado que los regímenes de bienestar social son incapaces o los políticos no están dispuestos a cargar con los costos de proteger a los más vulnerables; y la intensificación de la polarización económica y la exclusión, dentro y a través de los Estados» (Held; 2003: 98, 99).

Con la globalización económica, en palabras de Held y McGrew, se han globalizado la exclusión y la pobreza en los niveles nacional global, y en este sentido el mismo proyecto de globalización se convierte en su propia amenaza al crear profundas divisiones y tensiones entre los Estados y al interior de estos que se hacen visibles a través del resurgimiento de los fundamentalismos religiosos, la transnacionalización del crimen organizado y del terrorismo, la vuelta a los conflictos étnicos y religiosos y al incremento en el número de los Ilamados Estados fallidos (Castells, citado por Held y McGrew; 2003: 99). Como lo menciona Castells, «a menos que la globalización económica neoliberal sea domada, prosigue el argumento, surgirá una nueva barbarie a medida que los conflictos se extiendan a las zonas de paz [si es que queda alguna] globales alimentados por la intensificación de la pobreza, la exclusión, la vulnerabilidad y la desigualdad» (2003: 99), del mismo modo en que la distancia que separa al centro de las periferias se seguirá ahondando y seguirá generando focos de insurrección, protesta y violencia.

La globalización desde abajo, la alterglobalización o la antiglobalización, según como se quiera definir, es el principal objetivo de estos movimientos, de ahí que la oposición a la globalización neoliberal constituye su principal «adversario político-sistémico» (Iglesias; 2004: 3). En esta dirección, los movimientos que se han agrupado en contra de la globalización económica han adoptado como estrategia de acción colectiva la «desobediencia política» que, a su vez, se ha constituido en factor clave y determinante para definir y consolidar su identidad. 
Así como existe una unidad consensuada del enemigo o adversario al que los movimientos antiglobalización se oponen y contraponen su proyecto, sobresale dentro de las formas de acción colectiva adoptadas el modelo contracumbre, que constituye uno de los principales elementos diferenciadores de estos movimientos respecto a otros tipos de acción colectiva. El modelo contracumbre, como «acción colectiva conflictiva»y, por tanto, como un «modelo de enfrentamiento", ha sido "capaz de articular una movilización social contra el capitalismo visible en todo el mundo a partir de la creación de escenarios simbólicos de conflicto con el sistema", mediante la desobediencia civil y política, la espectacularidad mediática y el empleo de recursos informáticos y tecnológicos para difundir su mensaje (Iglesias; 2004: 3).

El movimiento alterglobalización constituye un claro ejemplo de cómo pueden ser articulados mecanismos sociales que provienen de las bases de la sociedad, pero que se erigen hasta diversos y amplios sectores locales, regionales e internacionales, constituyendo una estructura organizativa de doble dirección: de abajo hacia arriba y de arriba hacia abajo; así como representa la articulación sostenida por los novísimos movimientos sociales respecto al alcance e impacto de las acciones en el ámbito local, regional y global, debido en gran parte al «uso activo de la inmediatez y del alcance global de los modernos medios de comunicación (...) para articularse en la red global» (Sotolongo; 2006: 182).

Mediante el uso y aprovechamiento de las tecnologías informáticas, los movimientos alterglobalización, o comúnmente denominados antiglobalización, defienden una causa eminentemente política que encierra el ideal de «otra globalización», de «otro mundo posible», diferente al impuesto por la globalización de tinte neoliberal. De esta forma, la lucha de los movimientos antiglobalización es una lucha política que se dirige a "cambiar el curso de los destinos políticos neoliberales que la globalización ha tomado bajo la égida del capitalismo mundial» (Sotolongo; 2006: 184, 185).

En esta lucha por defender el proyecto de la alterglobalización, estos movimientos enfrentan el dilema acerca del predominio de la reforma sobre la revolución. El debate sobre revolución o reforma pone de manifiesto que muchos de los movimientos y grupos que entran dentro de la clasificación de antiglobalización, apuestan por una postura que no busca la toma del poder, sino que se dirige a incidir en el cambio de las relaciones de poder y así abogan por relaciones de igualdad que reemplacen la opresión, la exclusión y el dominio, mientras que otros tantos defienden la idea de una revolución como "cambio civilizacional» que requiere de tiempo para gestarse. «Reforma o revolución. Esta fisura carga con el peso de la tradición de la izquierda occidental. Es la fisura entre aquellos que piensan que es posible otro mundo a través de la transformación gradual del injusto mundo en que vivimos, empleando reformas legales y mecanismos de democracia representativa, y entre aquellos que piensan que el mundo que habitamos es básicamente un mundo capitalista, que este mundo nunca va a tolerar reformas que lo cuestionen y que, por tanto, debe ser destruido y reemplazado por un mundo socialista» (Souza; 188). 
Pero el debate o la discusión en torno a la reforma o a la revolución no es el único, ha venido acompañado de las diversas posturas alrededor de los temas sobre el socialismo o la emancipación social, el Estado, como enemigo o como aliado potencial, y la acción directa o institucional, que aunque no son posturas que se configuran con estos movimientos, sí coexisten al interior del FSM «sin perturbar su poder de agregación».

\section{EL CASO BOLIVIANO: ENTRE LO LOCAL Y LO GLOBAL}

Bolivia representa un buen ejemplo para analizar las dinámicas del movimiento antiglobalización, en un caso concreto que funde las dimensiones locales, regionales y globales que se encuentran insertas en las luchas emprendidas por el agua, por el comercio justo y en contra del libre comercio, por señalar algunas de las «batallas» que se han comenzado a librar desde este país.

La guerra del agua, Ilevada a Cabo en la ciudad de Cochabamba, Bolivia, logró poner de manifiesto que puede ser llevada a cabo una globalización desde abajo, diferente a la emprendida por las empresas transnacionales. Con esta "guerra", que se constituyó en una protesta local masiva, se logró la expulsión, en el año 2000, del consorcio privado encargado de gestionar el servicio de agua potable y de alcantarillado en esta ciudad. Las jornadas de protestas que finalizaron con «la batalla final» por la recuperación del agua generaron la atención no sólo nacional, sino también internacional, puesto que se convirtió en un prototipo de las posibilidades «alternativas» de solidaridad entre organizaciones y movimientos sociales del Norte y del Sur (Mayorga; 2008).

El Bolivia, este tipo de lucha se configura como un proceso en el que se combinan «los procesos de protesta global y local» en contra del libre comercio y en contra de las empresas transnacionales con fenómenos de carácter más local o nacional, como las fuertes críticas al sistema de partidos y, en general, al sistema imperante de exclusión política.

Con la guerra del agua, Ilevada a cabo en Cochabamba, se inaugura en el país un "ciclo de protestas populares contra los efectos de las políticas que privilegian la inversión extranjera», el ingreso "en la ola de manifestaciones internacionales contra la globalización neoliberal» y las protestas en contra del modelo de democracia pactada (Mayorga; 2008).

Los antecedentes de la guerra del agua hay que buscarlos a nivel internacional en 1994, con el inicio de la participación popular en la gestión local del desarrollo, con la primera marcha campesina de los productores de la hoja de coca en el Chapare, y con las movilizaciones de los pueblos indígenas de la región amazónica que demandaban sus derechos colectivos. A nivel internacional, los antecedentes son principalmente: la entrada en vigor del TLC entre EE.UU., México y Canadá, y el planteamiento de la propuesta del gobierno Clinton del ALCA.

En el año de 1999 se crea la Coordinadora por la Defensa del Agua y de la Vida. En el año 2000 se da la batalla final de la guerra del agua, en el mismo año en el que organizaciones sociales estable- 
cían un encuentro paralelo al Segundo Foro Mundial del Agua, Ilevado a cabo en La Haya. Varias de estas organizaciones sociales Ilegaron posteriormente a Cochabamba para apoyar a la coordinación y suscribir «la Declaración de Cochabamba», que «enfatiza el carácter del acceso al agua como un derecho humano» (Mayorga; 2008).

A partir de ese año, las protestas levadas a cabo en Bolivia comienzan a ser acompañadas e impulsadas por nuevas acciones de la sociedad civil. Como resultado de estas nuevas acciones surge el Movimiento Bolivariano de Lucha contra el ALCA, posteriormente denominado Movimiento Bolivariano por la Soberanía y la Integración Solidaria de los Pueblos: Contra el TLC y el ALCA.

En el año 2006, con la llegada al poder del MAS (Movimiento al Socialismo), a través de Evo Morales, los acercamientos entre Bolivia y EE.UU., que se venían Ilevando a cabo en los gobiernos anteriores de Carlos Mesa y Eduardo Rodríguez, Ilegan a su fin. Incluso, con el gobierno de Morales la política gubernamental se conectó fuertemente con las demandas de los movimientos sociales, entre estos el Movimiento Boliviano de Lucha contra el TLC y el ALCA. Tales vínculos impulsan la promoción desde el gobierno de «El Tratado de Comercio de los Pueblos- TCP», como «forma de integrar el comercio justo en los acuerdos intergubernamentales» (Mayorga; 2008).

El «retorno a las fuentes» o el regreso del servicio del agua a la administración pública viene acompañado de las masivas movilizaciones que se hicieron en Bolivia en contra de la implementación de los instrumentos y acuerdos de libre comercio, relacionados con la privatización de los servicios de agua potable.

Asimismo, el Movimiento Bolivariano de Lucha contra el TLC y el ALCA lideró la campaña en contra del libre comercio y a favor de otras formas de integración, con el apoyo de varias organizaciones de base, ong 's y fundaciones de la sociedad civil, a partir de campañas para recuperar los recursos naturales y, en general, para promover una integración «regional y continental», basada en el respeto por la soberanía, los recursos naturales, los derechos humanos y la democracia real y participativa (Mayorga; 2008). Para llevar a cabo estos objetivos, el Movimiento se encuentra vinculado a una red nacional e internacional, la Alianza Social Continental, que agrupa a movimientos de artesanos y campesinos, pequeños empresarios y organizaciones económicas campesinas, entre otros.

Respecto a su capacidad de influencia en las políticas públicas, el primer impacto significativo del movimiento fue lograr la modificación de la Ley de Agua Potable y Alcantarillado. Del mismo modo, el que Bolivia no sea un país negociador del TLC andino con Estados Unidos puede ser visto como una "victoria» del Movimiento. Por otra parte, "en cuanto a su impacto internacional, la guerra del agua en Cochabamba es el acontecimiento boliviano más publicitado en las redes de organizaciones y activistas contra los acuerdos de libre comercio en el mundo» (Mayorga; 2008: 80).

Por el momento se puede sostener la idea de que la guerra por el agua y la protesta generada en contra del libre comercio en Bolivia constituyen ejemplos clave al momento de analizar el impacto, 
no sólo local-nacional, sino también regional-global, y el alcance que han tenido movimientos antiglobalización en el mundo. Del mismo modo, el caso de las iniciativas por el comercio justo y en pro del Tratado de Comercio de los Pueblos, como «una propuesta boliviana para un comercio con justicia", va en concordancia con el movimiento por el comercio justo que tiene sus orígenes en décadas atrás con el propósito de «aliviar la pobreza en el sur, dando a los productores en África, Asia y América Latina oportunidades equitativas para acceder a los mercados del norte, y apuntar a construir relaciones sostenibles directas entre estos productores del sur y los consumidores en las regiones ricas del mundo» (Mayorga; 2008: 107).

El comercio justo es entendido por este movimiento como «una relación de socios en comercio, basada en el diálogo, la transparencia y el respeto, que busca una mayor equidad en el comercio internacional», de tal forma que se persigue un mejoramiento en las condiciones de vida de los productores, mayores oportunidades de desarrollo para aquellos productores que se encuentran en una situación de desventaja, la creación de conciencia entre los consumidores sobre las consecuencias sociales y económicas que genera el comercio internacional convencional y la protección de los derechos humanos (Mayorga; 2008).

Concretamente, respecto al comercio justo en Bolivia, sobresale la diversidad y heterogeneidad de la estructura organizativa de los grupos que promueven esta iniciativa; muchos de estos constituyen organizaciones tradicionales, mientras que otros se han asociado en cooperativas, así como algunos de estos grupos reciben asistencia y cooperación internacional, mientras que otros tantos funcionan de forma autogestionada.

La campaña por el comercio justo en Bolivia ha permitido que diversas experiencias de base para el desarrollo rural proyecten "la revitalización de la conciencia sobre los aportes culturales indígenas», en medio de una globalización económica caracterizada por la crisis recurrente. Parte del éxito de la campaña en Bolivia ha dependido de numerosos y diversos factores como la masiva participación en las convocatorias y actividades, el liderazgo de los dirigentes para convocar la activa participación e involucramiento de las comunidades, el empleo de los conocimientos locales como bandera de lucha y el apoyo de sectores externos en actividades de capacitación, difusión y financiamiento.

En relación con el apoyo externo que recibe la campaña por el comercio justo en Bolivia, se encuentra la vinculación de ésta con redes internacionales que promueven la campaña en la esfera global, como Global Exchange, TransFair, Aid to Artisans y Level Ground Trading, que se han constituido en promotoras de relaciones de comercialización internacional bajo la premisa del comercio justo (Mayorga; 2008: 119).

A pesar del esfuerzo por defender y hacer de esta causa un motivo de acción colectiva que vincule lo local y lo global, se han presentando también algunas dificultades en el camino. El relativo éxito en la comercialización se ha visto empañado por las dificultades que enfrentan los productores de productos elaborados, puesto que «aun en los ámbitos del comercio justo los productores nacionales exportan materias primas y se sujetan a las condiciones del mercado» (Mayorga; 2008: 123). 
Sin embargo, con obstáculos o sin ellos, la campaña por el comercio justo en Bolivia ha logrado trascender la acción local por medio de la propuesta desde el gobierno del Tratado de Comercio de los Pueblos (TCP) con el eje rector del "comercio con justicia" y como una alternativa a los tratados de libre comercio impulsados por Estados Unidos. El TCP, al establecer el comercio no como un fin en sí mismo, sino como un medio para dar solución a las necesidades de los pueblos, defiende la diversidad cultural, aboga por la recuperación de la reciprocidad de las culturas indígenas, por el cuidado del medio ambiente y, en este sentido, por una convivencia sostenible con la naturaleza, así como por la defensa de la soberanía de los países (Mayorga; 2008: 131).

Por último, cabe anotar que las luchas por el agua, en contra del TLC y por la promoción del comercio justo en Bolivia, representan ejemplos claros sobre cómo las experiencias locales que se contraponen a los efectos negativos de la globalización económica neoliberal repercuten en la formulación de propuestas y de políticas de alcance nacional y regional que plantean una «reinserción alterna» del país y de la región en la dinámica de las relaciones económicas internacionales.

\section{CONCLUSIONES}

Dentro del conjunto de efectos sociopolíticos que ha generado la globalización económica se encuentra el surgimiento de los movimientos antiglobalización como formas de acción colectiva, agrupadas en torno a la causa de "otro mundo es posible» y bajo un modelo de alterglobalización que reivindique a países y a los pueblos excluidos, oprimidos y perdedores del neoliberalismo. La confluencia de diversos movimientos, grupos y organizaciones alrededor de la causa antiglobalizadora hace notable el tipo y el alcance de los efectos que los procesos y los temas globales han tenido en diversas partes del mundo, en las que se genera una «respuesta similar». Del mismo modo, las respuestas similares y simultáneas que han surgido en diferentes lugares del planeta, pone de manifiesto la capacidad de las múltiples y diversas organizaciones para establecer redes de cooperación, apoyo y de oportunidades, como componentes estructurales, para darle un alcance mayor a sus acciones y proyectos, así como para aprovechar y difundir globalmente su mensaje de globalización alternativa en diferentes frentes.

Sin embargo, dadas las características distintivas del movimiento antiglobalización, aún está latente la pregunta por la eficacia de sus acciones cuando el sistema-mundo capitalista imperante continúa reproduciendo inmensa desigualdad social, considerable deterioro medioambiental, enormes brechas en la distribución de la riqueza y gran precariedad en las relaciones laborales de producción. En este sentido, la pregunta se orienta a plantear si es posible un modelo alternativo al capitalismo, aun cuando éste sigue representando enormes beneficios a los más poderosos, a aquellos que lo dirigen y orientan, o si aquello por lo que abogan los grupos y movimientos alterglobalización es por un reparto más justo de los beneficios que produce el capitalismo pero, como bien se señala dentro del mismo sistema capitalista, de ahí que sus propuestas puedan entenderse como partes insertas dentro de la economía-mundo vigente, como planes para hacer del sistema un modelo justo, sin la necesidad de transformarlo radicalmente o sustituirlo por otro. 
No obstante, es importante resaltar la configuración de la acción colectiva que envuelve a estos movimientos, debido al auge o adherencia considerable y visiblemente identificable en los miles de manifestantes que han adoptado la causa alterglobalización. En otras palabras, la misma globalización ha posibilitado que miles de personas alrededor del mundo entren en sintonía con la propuesta de un mundo más justo, de otro mundo posible, reafirmando el derecho de los pueblos a ser tratados de igual forma y a gozar de los plenos beneficios que en este momento sólo unos pocos países detentan.

\section{BIBLIOGRAFÍA}

Arrighi, G., (1999). El largo siglo XX. Dinero y poder en los orígenes de nuestra época. Madrid: Akal. Introducción y epílogo.

Beck, U., (2004). ¿Qué es la globalización? Falacias del globalismo, respuestas a la globalización. Barcelona: Paidós. Caps.: I- IV.

Canclini, N., (2000). La globalización imaginada. México: Paidós. Caps.: 1 y 2.

De Souza Santos, B. (2005), «El Foro Social Mundial. Hacia una antiglobalización hegemónica», en Amin, S., Houtart, F., (eds.), Globalización de las resistencias. El estado de las luchas 2005. Madrid: Icaria.

Gómez, J., (2004). «De Porto Alegre a Mumbai. El foro social mundial y los retos del movimiento altermundista», en Ceceña, E, (comp.), Hegemonías y emancipaciones en el siglo XXI. Ana Esther Ceceña (comp.). Buenos Aires: CLACSO.

Held, D. y McGrew, A., (2003). Globalización / Antiglobalización. Sobre la reconstrucción del orden global. Barcelona: Paidós. Caps.: 1- 7.

Iglesias, P., (2004). «Los movimientos globales de Seattle a Praga. El modelo contracumbre como nueva forma de acción colectiva», ponencia presentada en el VIII Congreso de la Federación Española de Sociología, en Alicante-España, 23- 25 de septiembre.

Mayorga, Fernando (2008). El movimiento antiglobalización en Bolivia: Procesos globales e iniciativas locales en tiempos de crisis y cambios. La Paz: UNRISD.

Pérez, C., (2004). Revoluciones tecnológicas y capital financiero. La dinámica de las grandes burbujas financieras y las épocas de bonanza. México: Siglo XXI. Cap. 10.

Sandoval, C., (2009). «Gobiernos electrónicos y acción colectiva a través del internet: Dinámicas en la Región Andina", en Revista de Relaciones Internacionales, Estrategia y Seguridad, 4 (1): 31-53. Artículo disponible en http://www.umng.edu.co/docs/revrelinter/Vol4No1/3-Dr.CarlosGermanSandoval.pdf.

Sotolongo, P., y Delgado, C., (2006). «Una mirada nueva a la globalización», en La revolución contemporánea del saber y la complejidad social. Hacia unas ciencias sociales de nuevo tipo. Buenos Aires: CLACSO.

Stiglitz, J., (2002). El malestar en la globalización. México: Taurus. Caps.: 1 y2. 
Wallerstein, I., (2008). Impensar las ciencias sociales. México: Siglo XXI. , (2005). Análisis de sistemas- mundo: Una introducción. México: Siglo XXI. ,'(2004). Capitalismo histórico y movimientos antisistémicos. Madrid: Akal, Cap. V. , (2004). «¿Después del desarrollismo, qué?», ponencia presentada en la Conferencia «Development

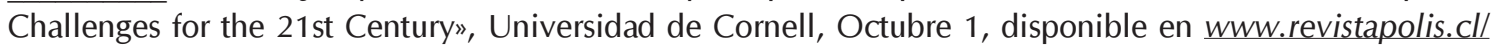
polis\%20final/13/doc/walle.doc, consultado el 20 de julio de 2009. 